\title{
FAKTOR RISIKO YANG BERPENGARUH DENGAN KEJADIAN KANKER SERVIKS DI RSUD DR. H. ABDUL MOELOEK PROVINSI LAMPUNG
}

\author{
Ravika Chandrawati \\ Universitas Malahayati \\ Email: ravikachandra89@gmail.com
}

\begin{abstract}
Abstrack: Risk Factors Affecting the Occurrence of Cervical Cancer in Dr . H. Abdul Moeloek Hospital, Lampung. Cervical cancer is the most types of cancer experienced by women around the world. In Indonesia, each year more than 15,000 detected cases of cervical cancer and about 8,000 of these cases end in death. Bandar Lampung is constantly increasing, which is 356 cases in 2013 and 383 cases in 2014. This study was to determine risk factors affecting the occurrence of cervical cancer in Dr. H Abdul Moeloek Hospital, Lampung. Research types was quantitative with analytic design, case control approach. Population were the entire inpatient obstetrics at the Dr. H. Abdul Moeloek Hospital, Lampung, 2015 which amounted to 3,499 people. Samples cases were 50, and 50 as controls. Data were analyze by univariate, bivariate with chisquare test, and multivariate with logistic regression. The results showed that there was an influence of age $(p=0.006$; OR = 23.143), marriageable age $(p=0,000 ; O R=4.644)$, the effect of parity $(\mathrm{p}=0,000 ; \mathrm{OR}=6.143)$, education $(\mathrm{p}=0,000 \mathrm{OR}=4.696)$, the jobs $(\mathrm{p}=0,000 ; \mathrm{OR}=$ $7.333)$, and the number of marriages $(p=0,000 ; O R=6.655)$ to the incidence of cervical cancer in the Dr.H. Abdul Moeloek hospital, Lampung, 2015. The most dominant variable that influence the incidence of cervical cancer in the Dr.H. Abdul Moeloek hospital, Lampung, 2015 is the variable age $(\mathrm{p}=0,000 ; \mathrm{OR}=15.653)$.
\end{abstract}

Keywords: Risk Factor, Cancer, Cervical Cancer

\begin{abstract}
Abstrak: Faktor-faktor Risiko yang Berpengaruh dengan Kejadian Kanker Serviks di RSUD DR.H.Abdul Moeloek Provinsi Lampung. Kanker serviks merupakan jenis kanker terbanyak yang dialami oleh wanita di seluruh dunia. Di Indonesia, setiap tahunnya terdeteksi lebih dari 15.000 kasus kanker serviks dan sekitar 8.000 kasus diantaranya berakhir dengan kematian. Di Bandar Lampung terus mengalami peningkatan, yaitu 356 kasus di tahun 2013 dan 383 kasus di tahun 2014. Jenis penelitian kuantitatif dengan desain analitik menggunakan pendekatan case control. Populasi penelitian adalah seluruh pasien rawat inap kebidanan di RSUD Dr. H. Abdul Moeloek Provinsi Lampung tahun 2015 yang berjumlah 3.499 orang. Sampel yang didapat yaitu 50 kasus dan 50 kontrol. Analisis data menggunakan univariat, bivariat dengan uji chi-square, dan multivariat dengan regresi logistik. Hasil analisis bivariat menunjukkan bahwa ada pengaruh usia, usia menikah, paritas, pendidikan, pekerjaan dan jumlah pernikahan dengan kejadian kanker serviks d RSUD Dr.H. Abdul moeloek Provinsi Lampung Tahun 2015. Variabel paling dominan yang berpengaruh dengan kejadian kanker serviks d RSUD Dr.H. Abdul moeloek Provinsi Lampung Tahun 2015 adalah variabel usia $(\mathrm{p}=0,000 ; \mathrm{OR}=15,653)$.
\end{abstract}

Kata Kunci: Faktor Risiko, Kanker, Kanker Serviks

Kanker serviks dipicu oleh organisme yang sangat kecil, yang tergolong mikroorganisme yang bernama Virus Human Papilloma atau biasa disebut dengan HPV (Human Papilloma Virus). Penyebab kanker ini didominasi oleh keberadaan HPV yang menyerang leher rahim. Jenis HPV yang diduga menjadi penyebab kanker serviks yakni tipe 16 dan 18 dimana tipe 16 mendominasi kasus kanker serviks $50-60 \%$ dan $10-15 \%$ untuk tipe 18. Proses infeksi HPV menjadi kanker serviks memerlukan waktu yang cukup lama, yaitu 10-20 tahun (Savitri, 2015:107).

Menurut WHO, Indonesia merupakan negara dengan jumlah penderita kanker serviks nomor dua terbanyak pada perempuan berusia 15-45 tahun setelah kanker payudara. Pasalnya kanker ini sulit sekali dideteksi hingga penyakit telah mencapai stadium lanjut. Di Indonesia, setiap tahunnya terdeteksi lebih dari 15.000 kasus kanker serviks dan sekitar 8.000 kasus diantaranya berakhir dengan kematian. Setiap hari muncul 40-45 kasus baru, 20-25 orang 
meninggal, berarti setiap satu jam diperkirakan satu orang perempuan meninggal dunia karena kanker serviks (Arum, 2015:78).

Pusat Data dan Informasi Kementerian Kesehatan RI menerangkan bahwa penyakit kanker serviks dan payudara merupakan penyakit kanker dengan prevalensi tinggi di Indonesia pada tahun 2013, yaitu kanker serviks sebesar $0,8 \%$. Dan kanker payudara $0,5 \%$. Berdasarkan hasil estimasi jumlah kasus baru dan jumlah kematian akibat kanker di Rumah Sakit Kanker Dharmais, kanker serviks terus mengalami peningkatan yaitu 296 kasus pada tahun 2010, 300 kasus pada tahun 2011, 343 kasus pada tahun 2012, 356 pada tahun 2013 dan 383 kasus di tahun 2014.

Tingginya kejadian kanker serviks di Provinsi Lampung bisa dilihat dari data di RSUD Dr. H Abdul Moeloek yang merupakan rumah sakit type B yang terletak di Bandar Lampung. RSUD Dr. H Abdul Moeloek saat ini menjadi RS rujukan tertinggi untuk Rumah Sakit di 15 kabupaten/kota di Provinsi Lampung. Berdasarkan data yang didapat dari ruang instalasi rawat inap delima RSUD Dr. H. Abdul Moeloek Provinsi Lampung di tahun 2015 mendapati kasus kanker serviks sebanyak 109 kasus dimana kanker serviks menduduki peringkat pertama dari semua jenis kanker alat reproduksi pada wanita. (Rekam medik RSUD Dr. H. Abdul Moeloek Provinsi Lampung).

Angka kematian kanker serviks di Indonesia tergolong tinggi karena sebagian besar disebabkan oleh keterlambatan dalam diagnosis. Ketika memeriksakan kondisinya, biasanya kanker sudah menyebar ke organ lain di dalam tubuh. Hal ini yang menyebabkan pengobatan yang dilakukan semakin sulit. Padahal diketahui bahwa penyakit kanker serviks ini dapat dicegah melalui skrining dan vaksinasi (Savitri, 2015: 96).

Kegiatan deteksi dini kanker serviks telah dilaksanakan di seluruh provinsi di Indonesia, meliputi 304 dari seluruh kabupaten/kota di Indonesia dan 1986 puskesmas. Jumlah kumulatif yang telah di skrining di Indonesia tahun 20072014 yaitu sebanyak 904.099 orang. Dari jumlah yang telah di skrining tersebut, 1.056 (1,2 per 1000) menunjukkan adanya suspect kanker leher rahim. Sedangkan Pemerintah Provinsi Lampung telah melakukan upaya dengan melatih lebih kurang 43 puskesmas dalam melakukan metode Inspeksi Visual Asam Asetat (IVA) (Wahidin, 2014)

\section{METODE PENELITIAN}

Jenis penelitian kuantitatif dengan desain analitik menggunakan pendekatan case control. Penelitian dilakukan di RSUD Dr. H. Abdul Moeloek Provinsi Lampung. Populasi dalam penelitian ini yaitu seluruh pasien rawat inap kebidanan ruangan delima di RSUD Dr. H. Abdul Moeloek Provinsi Lampung tahun 2015 yang berjumlah 3.499 orang. Sampel kasus dan kontrol yang masing-masing berjumlah 50 orang. Pengumpulan data dilakukan dengan menggunakan data sekunder dari catatan rekam medik RSUD Dr. H. Abdul Moeloek Provinsi Lampung. Analisis data dengan univariat, bivariat dengan uji chi-square dan multivariat dengan uji regresi logistik.

\section{HASIL}

Berdasarkan hasil pengumpulan data dan analisis data yang dilakukan, maka didapatkan hasil:

\section{A. ANALISIS UNIVARIAT}

Tabel 1. Hasil Analisis Univariat

\begin{tabular}{lcc}
\hline Variabel & n & \% \\
\hline Usia & & \\
\hline Berisiko & 59 & 59 \\
\hline Tidak Berisiko & 41 & 41 \\
\hline Total & 100 & 100 \\
\hline Usia Menikah & & \\
\hline Berisiko & 44 & 59 \\
\hline Tidak Berisiko & 56 & 41 \\
\hline Total & 100 & 100 \\
\hline Paritas & & \\
\hline Berisiko & 32 & 32 \\
\hline Tidak Berisiko & 68 & 68 \\
\hline Total & 100 & 100 \\
\hline Pendidikan & & \\
\hline Berisiko & 63 & 63 \\
\hline Tidak Berisiko & 37 & 37 \\
\hline Total & 100 & 100 \\
\hline Pekerjaan & & \\
\hline Berisiko & 31 & 31 \\
\hline Tidak Berisiko & 69 & 69 \\
\hline Total & 100 & 100 \\
\hline Jumlah & & \\
\hline Pernikahan & & 33 \\
\hline Berisiko & 33 & 67 \\
\hline Tidak Berisiko & 67 & 100 \\
\hline Total & 100 & \\
\hline & & \\
\hline
\end{tabular}


Hasil ini menggambarkan distribusi frekuensi responden. Diketahui bahwa terdapat 59 responden $(59 \%)$ dengan usia berisiko (>35 tahun), 44 responden (44\%) dengan usia menikah berisiko ( $<20$ tahun), 32 responden $(32 \%)$ paritas berisiko $(>3), 63$ responden $(63 \%)$ dengan pendidikan berisiko (rendah), 31 responden $(31 \%)$ dengan pekerjaan berisiko (kasar) dan 33 responden (33\%) dengan jumlah pernikahan berisiko (>1 kali).

\section{B. ANALISIS BIVARIAT}

Analisa ini dilakukan untuk melihat variabel yang berhubungan dengan kejadian kanker serviks di RSUD Dr. H. Abdul Moeloek Provinsi Lampung.

Diketahui seluruh faktor risiko berhubungan dengan kejadian kanker serviks ( $p$ value $<0,05)$ yaitu usia pasien, usia menikah, paritas, pendidikan, pekerjaan, dan jumlah pernikahan.

\section{Tabel 2. Hasil Analisis Bivariat}

\begin{tabular}{|c|c|c|}
\hline \multirow{2}{*}{ Variabel } & \multicolumn{2}{|c|}{$\begin{array}{c}\text { Kejadian Kanker } \\
\text { Serviks }\end{array}$} \\
\hline & Kasus & Kontrol \\
\hline \multicolumn{3}{|l|}{ Usia Pasien } \\
\hline Berisiko & $45(76,3 \%)$ & $14(23,7 \%)$ \\
\hline Tidak Berisiko & $5(12,2 \%)$ & $36(87,8 \%)$ \\
\hline \multicolumn{3}{|c|}{$p$ value $=0,000 \mathrm{OR}=23,143(7,618-70,308)$} \\
\hline \multicolumn{3}{|l|}{ Usia Menikah } \\
\hline Berisiko & $31(70,5 \%)$ & $13(29,5 \%)$ \\
\hline Tidak Berisiko & $19(33,9 \%)$ & $37(66,1 \%)$ \\
\hline \multicolumn{3}{|c|}{$p$ value $=0,000 \mathrm{OR}=4,644(1,981-10,883)$} \\
\hline \multicolumn{3}{|l|}{ Paritas } \\
\hline Berisiko & $25(78,1 \%)$ & $7(21,9 \%)$ \\
\hline Tidak Berisiko & $25(36,8 \%)$ & $43(63,2 \%)$ \\
\hline \multicolumn{3}{|c|}{$p$ value $=0,000 \mathrm{OR}=6,143(2,323-16,242)$} \\
\hline \multicolumn{3}{|l|}{ Pendidikan } \\
\hline Berisiko & $40(63,5 \%)$ & $23(36,5 \%)$ \\
\hline Tidak Berisiko & $10(27,0 \%)$ & $27(73,0 \%)$ \\
\hline \multicolumn{3}{|c|}{$p$ value $=0,000 \mathrm{OR}=4,696(1,931-11,418)$} \\
\hline \multicolumn{3}{|l|}{ Pekerjaan } \\
\hline Berisiko & $25(80,6 \%)$ & $6(19,4 \%)$ \\
\hline Tidak Berisiko & $25(36,2 \%)$ & $44(63,8 \%)$ \\
\hline \multicolumn{3}{|c|}{$p$ value $=0,000 \mathrm{OR}=7,333(2,652-20,282)$} \\
\hline \multicolumn{3}{|l|}{$\begin{array}{l}\text { Jumlah } \\
\text { Pernikahan }\end{array}$} \\
\hline Berisiko & $26(78,8 \%)$ & $7(21,2 \%)$ \\
\hline Tidak Berisiko & $24(35,8 \%)$ & $43(64,2 \%)$ \\
\hline \multicolumn{3}{|c|}{$p$ value $0,000 \mathrm{OR}=6,655(2,516-17,600)$} \\
\hline
\end{tabular}

\section{ANALISIS MULTIVARIAT}

Analisa ini dilakukan untuk melihat variabel paling dominan berpengaruh dengan kejadian kanker serviks di RSUD Dr. H. Abdul Moeloek Provinsi Lampung. Hasil dapat terlihat pada tabel berikut:

Tabel 3. Hasil Analisis Multivariat Tahap I

\begin{tabular}{lcc}
\multicolumn{1}{c}{ Variabel } & p value & OR \\
\hline Usia Pasien & 0,000 & 12,829 \\
\hline Usia Menikah & 0,004 & 7,808 \\
\hline Paritas & 0,673 & 1,538 \\
\hline Pendidikan & 0,347 & 1,978 \\
\hline Pekerjaan & 0,094 & 3,363 \\
\hline Jumlah Pernikahan & 0,01 & 7,036 \\
\hline
\end{tabular}

Berdasarkan hasil analisis, terdapat variabel yang memiliki nilai $p$-value $\geq 0,05$ yaitu paritas $(p=0,673)$, pendidikan $(p=0,347)$ dan Pekerjaan $(p=0,094)$. Maka variabel yang memiliki nilai $p$ value paling besar yakni variable paritas $(p=0,673)$ harus dikeluarkan dan tidak diikut sertakan pada perhitungan multivariat tahap selanjutnya.

Tabel 4. Hasil Analisis Multivariat Tahap Kedua

\begin{tabular}{lcc}
\hline \multicolumn{1}{c}{ Variabel } & p value & OR \\
\hline Usia Pasien & 0,000 & 14,242 \\
\hline Usia Menikah & 0,002 & 8,349 \\
\hline Pendidikan & 0,317 & 2,059 \\
\hline Pekerjaan & 0,089 & 3,41 \\
\hline Jumlah Pernikahan & 0,01 & 7,068 \\
\hline
\end{tabular}

Berdasarkan tabel di atas dapat diketahui bahwa dari 5 variabel yang diduga berhubungan dengan kanker serviks, terdapat variabel memiliki nilai $p$-value $\searrow 0,05$ yaitu pendidikan $(p=0,317)$ dan pekerjaan $(p=0,089)$. Maka variabel yang memiliki nilai $p$-value paling besar yakni variable pendidikan $(p=0,317)$ harus dikeluarkan dan tidak diikut sertakan pada perhitungan multivariat tahap selanjutnya.

Tabel 5. Hasil Analisis Multivariat Tahap Ketiga

\begin{tabular}{llr}
\multicolumn{1}{c}{ Variabel } & p value & \multicolumn{1}{c}{ OR } \\
\hline Usia Pasien & 0,000 & 15,653 \\
\hline Usia Menikah & 0,000 & 8,836 \\
\hline Pekerjaan & 0,000 & 4,261 \\
\hline Jumlah Pernikahan & 0,000 & 6,079 \\
\hline
\end{tabular}


Berdasarkan tabel di atas, terlihat bahwa variabel yang mempunyai nilai $p$-value $>0,05$ sudah tidak ada, sehingga tidak ada variabel yang harus dikeluarkan dari model. Hasil akhir multivariat dapat diketahui bahwa terdapat faktor yang paling dominan berpengaruh dengan kanker serviks di RSUD Dr. H. Abdul Moeloek Provinsi Lampung Tahun 2015 yaitu variabel usia pasien ( $p$-value $=0,000$ dan $\mathrm{OR}=15,653)$.

\section{UJI INTERAKSI}

Setelah diperoleh variabel yang masuk dalam model, kemudian dilakukan identifikasi interaksi antar variabel yang masuk dalam model dengan berdasarkan pada substansi, dalam hal ini peneliti menganggap bahwa secara substansi ada beberapa pertimbangan interaksi, yaitu:

a. Interaksi usia dengan usia menikah

b. Interaksi usia dengan paritas

c. Interaksi usia menikah dengan paritas

Tabel 6. Hasil Uji Interaksi

\begin{tabular}{lcc}
\multicolumn{1}{c}{ Variabel } & p-value & OR \\
\hline $\begin{array}{l}\text { Usia dengan Usia } \\
\text { Menikah }\end{array}$ & 0,215 & 0,182 \\
\hline Usia dengan Paritas & 0,999 & 0,000 \\
\hline $\begin{array}{l}\text { Usia Menikah dengan } \\
\text { Paritas }\end{array}$ & 0,320 & 2,506 \\
\hline
\end{tabular}

Hasil pengujian menunjukkan bahwa semua variabel yang diinteraksikan keluar dari model ( $p$-value $>0,05)$ sehingga dapat dikatakan tidak ada interaksi antar variabel independen. Berdasarkan hasil analisis interaksi tersebut maka tidak ada interaksi yang dapat masuk ke dalam model, maka model akhir yang diperoleh adalah model tanpa interaksi sebagai berikut:

Tabel 7. Hasil Akhir Analisis Multivariat

\begin{tabular}{llr}
\hline \multicolumn{1}{c}{ Variabel } & p-value & \multicolumn{1}{c}{ OR } \\
\hline Usia Pasien & 0,000 & 15,653 \\
\hline Usia Menikah & 0,000 & 8,836 \\
\hline Pekerjaan & 0,000 & 4,261 \\
\hline Jumlah Pernikahan & 0,000 & 6,079 \\
\hline
\end{tabular}

\section{PEMBAHASAN}

\section{A. ANALISIS BIVARIAT}

\section{Usia Pasien}

Pada peneltian ini didapatkan hubungan antara usia pasien dengan kejadian kanker serviks ( $p$-value $=0,000 ; \quad \mathrm{OR}=23,143)$. Menurut Arum
(2015), semua usia wanita berpotensi terkena kanker serviks. Wanita usia muda kini sudah banyak terkena kanker serviks. Namun puncak usia penderita kanker serviks di Indonesia masih didominasi usia 40-45 tahun. Hasil penelitian ini sejalan dengan penelitian yang dilakukan Wahyuningsih yang menyebtkan bahwa wanita dengan usia $>35$ tahun memiliki kecenderungan untuk terjadi kanker serviks lebih tinggi dibandingkan dengan usia $\leq 35$ tahun.

\section{Usia Menikah}

Pada peneltian ini didapatkan hubungan antara usia menikah dengan kejadian kanker serviks ( $p$-value $=0,000 ; \mathrm{OR}=2,330)$. Menurut pendapat Savitri (2015) bahwa sebelum usia 20 tahun organ reproduksi wanita belum memiliki tingkat kematangan yang sesuai. Hasil penelitian ini sejalan dengan penelitian yang dilakukan oleh Melva (2008) yang menemukan bahwa kejadian kanker serviks proporsi terbesar terjadi pada kelompok usia menikah <20 tahun $(60 \%)$ dan pada kelompok usia menikah $\geq 20$ tahun $(60,8 \%)$.

\section{Paritas}

Pada peneltian ini didapatkan hubungan antara paritas dengan kejadian kanker serviks ( $p$ value $=0,000 ; \quad \mathrm{OR}=6,143)$. Menurut Savitri (2015) paritas atau kelahiran yang paling optimal adalah kelahiran sampai ketiga kali. Semakin banyak proses melahirkan yang dialami oleh seorang ibu maka semakin tinggi risikonya untuk terkena kanker serviks. saat proses melahirkan janin tentu saja akan keluar melalui serviks yang merupakan leher rahim, jembatan antara rahim dan vagina. Keluarnya janin akan menimbulkan trauma pada serviks. Jika serviks mengalami kelahiran terus menerus maka serviks juga akan semakin mengalami trauma. Penelitian ini sejalan dengan penelitian Setyarini (2009) diperoleh nilai $p$-value $=0,033$ yang berarti ada hubungan antara paritas dengan kanker serviks.

\section{Pendidikan}

Pada peneltian ini didapatkan hubungan antara pendidikan dengan kejadian kanker serviks ( $p$-value $=0,000 ; \quad \mathrm{OR}=4,694)$. Menurut Savitri (2015) Tingkat pendidikan dalam hal ini mempengaruhi proses belajar, semakin tinggi tingkat pendidikan seseorang maka semakin mudah pula orang tersebut untuk menerima informasi. Tinggi rendanhnya tingkat pendidikan berkaitan dengan sosio ekonomi, kehidupan seks, dan kebersihan.Hasil penelitian ini sejalan dengan penelitian yang dilakukan oleh Melva (2008) di RSUP H. Adam Malik yang menemukan bahwa dari seluruh responden yang 
berjumlah 60 orang, yang berpendidikan rendah yaitu dibawah SMP sebanyak 45 penderita, sedangkan yang berpendidikan tinggi, di atas SMA hanya 15 penderita.

\section{Pekerjaan}

Pada peneltian ini didapatkan hubungan antara pekerjaan dengan kejadian kanker serviks ( $p$-value $=0,000 ; \mathrm{OR}=7,333$ ). Menurut pendapat Rasjidi (2009), pekerjaan merupakan salah satu faktor risiko kanker serviks. Pekerjaan mempunyai hubungan dengan kejadian kanker serviks, dimana wanita pekerja kasar seperti buruh dan petani memperlihatkan kemungkinan terkena kanker serviks lebih besar dibandingkan wanita pekerja ringan atau bekerja di kantor. Wanita pekerja kasar disebabkan karena standar kebersihan yang tidak baik. Sejalan dengan hasil penelitian di RSUD Arifin Achmad oleh Damayanti pada tahun 2013, wanita dengan pekerjaan berat lebih berisiko menderita kanker serviks dibandingkan dengan wanita dengan pekerjaan ringan.

\section{Jumlah Pernikahan}

Pada peneltian ini didapatkan hubungan antara paritas dengan kejadian kanker serviks ( $p$ value $=0,000, \mathrm{OR}=6,655$ ). Setiap berhubungan seksual dengan satu pasangan baru, kesempatan untuk terkena penyakit akibat hubungan seksual semakin besar. Hal ini berlaku baik pada istri maupun suami. Hasil penelitian ini sejalan dengan penelitin yang dilakukan oleh Tira (2007) yang menemukan bahwa berdasarkan hasil uji odds ratio dengan tingkat kepercayaan 95\% diperoleh nilai OR 12,048 yang berarti jumlah pernikahan lebih dari 1 kali berisiko menderita kanker serviks 12,048 kali dibandingkan ibu dengan jumlah pernikahan 1 kali.

\section{B. ANALISIS MULTIVARIAT}

Berdasarkan hasil analisis multivariat variabel yang dapat masuk dalam model akhir adalah variabel usia pasien, usia menikah, pekerjaan dan jumlah pernikahan, berarti bahwa ada empat faktor prediksi kejadian kanker serviks di RSUD Dr. H. Abdul Moleoek Provinsi Lampung, bahwa variabel usia pasien merupakan faktor paling dominan terhadap kejadian kanker serviks di RSUD Dr. H. Abdul Moleoek Provinsi Lampung, dengan ( $p$-value $=0,000$ dan $\mathrm{OR}=15,653)$. karena memiliki nilai $\mathrm{p}$ paling kecil dan OR paling besar, angka ini menunjukkan bahwa wanita yang berusia $>35$ tahun berisiko mengalami kanker serviks sebesar 15,563 kali dibandingkan dengan wanita yang berusia $\leq 35$ tahun.

\section{SIMPULAN}

Berdasarkan hasil penelitian yang telah dilakukan dapa disimpulkan ada hubungan yang bermakna antara usia pasien, usia menikah, paritas, pendidikan, pekerjaan dan jumlah pernikahn dengan kejadian kanker serviks di RSUD Dr. H. Abdul Moeloek Provinsi Lampung.

\section{SARAN}

\section{a. Bagi RSUD Dr. H. Abdul Moeloek Provinsi Lampung}

Memberikan laporan kepada Dinas kesehatan provinsi bahwa faktor usia merupakan faktor yang paling dominan berpengaruh dengan kejadian kanker serviks agar dapat ditindaklanjuti oleh kabupaten/kota untuk dapat dilakukan pencegahan primer.

\section{b. Bagi Dinas Kesehatan Provinsi Lampung}

Dapat melakukan sosialisasi kepada kabupaten/kota mengenai pencegahan primer, sekunder dan tersier serta menghimbau kepada masyarakat agar melakukan deteksi dini kanker serviks bik dengan IVA atau pap smear agar kanker serviks dapat terdeteksi lebih awal yang akan memungkinkan tingkat kesembuhan lebih tinggi.

\section{c. Bagi Masyarakat}

Diharapkan dapat melakukan pencegahan primer dengan menjuhkan faktor risiko, misalkan dengan menikah diatas usia 20 tahun dan melakukan vaksinasi serta melakukan deteksi dini kanker serviks dengan IVA atau pap smear agar kanker serviks terdeteksi sejak dini.

\section{DAFTAR PUSTAKA}

Arum, S.P. 2015. Stop Kanker Serviks. Yogyakarta: Penerbit Notebook.

Darmayanti. 2014. Faktor-faktor yang berhubungan dengan kanker leher rahim di RSUD Ulin Banjarmasin. Poltekkes Kemenkes Banjarmasin. Diunduh tanggal 17 Juni 2016. 
Hestuningtyas, N.S. 2015. Rekam Medik RSUD Dr H. Abdul Moeloek Provinsi Lampung.

Melva. 2008. Faktor-faktor yang mempengaruhi kejadian kanker leher rahim pada penderita yang datang berobat di RSUP $H$. Adam Malik Medan Tahun 2008. repository.usu.ac.id. Universitas Sumatera Utara.

Rasjidi, I. 2009. Epidemiologi Kanker Serviks. Indonesian Journal of Cancer III (3) (Diunduh tanggal 5 Maret 2016).

Savitri, A dkk. 2015. Kupas Tuntas Kanker Payudara, Leher Rahim, dan Rahim. Yogyakarta: Penerbit Pustaka Baru Press.

Setyarini, E. 2009. Faktor-faktor Yang Berhubungan dengan Kejadian Kanker
Leher Rahim Di RSUD DR. Moewardi. Surakarta (Diunduh tanggal 23 Maret 2016).

Tira, D.S. 2008. Risiko Jumlah Perkawinan, Riwayat Abortus. Dan Pemakaian Alat Kontrasepsi Hormonal Terhadap Kejadian Kanker Serviks di Rumah Sakit Pelamonia Makassar Tahun 2004-2007 (Diunduh tanggal 23 Maret 2016)

Wahidin, M. 2014. Deteksi Dini Kanker Payudara dan Kanker Leher Rahim di Indonesia Tahun 2007-2014. Jurnal Pengendalian Penyakit dan Penyehatan Lingkungan. Jakarta. 